\title{
THE RESEARCH OF CARGO COMPANIES IN TERMS OF CUSTOMER SATISFACTION AND COMPANY REPUTATION
}

\author{
DOI: 10.17261/Pressacademia.2018.874 \\ PAP- V.7-2018(27)-p.165-169
}

Mustafa Alp ${ }^{1}$, Nilay Koleoglu², Binnaz Cinar ${ }^{3}$

${ }^{1}$ Çanakkale Onsekiz Mart Üniversitesi, Sosyal Bilimler Enstitüsü Ișletme ABD Doktora Öğrencisi, Çanakkale. alpmust@hotmail.com, ORCID: 0000-0002-9578-4551

${ }^{2}$ Çanakkale Onsekiz Mart Üniversitesi, İşletme Anabilim Dalı, Sayısal Yöntemler, Çanakkale. nkoleoglu@yahoo.com, ORCID: 0000-0002-6153-719x

${ }^{3}$ Bandırma Onyedi Eylül Üniversitesi, Sosyal Bilimler Enstitüsü İşletme ABD Doktora Öğrencisi, Balıkesir. binnazcinar62@gmail.com, ORCID: 0000-0002-0323-9864

\section{To cite this document}

Alp, M., Koleoglu, N., Cinar, B. (2018). The research of cargo companies in terms of customer satisfaction and company reputation. PressAcademia Procedia (PAP), V.7, p.165-169.

Permemant link to this document: http://doi.org/10.17261/Pressacademia.2018.874

Copyright: Published by PressAcademia and limited licenced re-use rights only.

\section{ABSTRACT}

Purpose- The main aim of this study is to determine the effect of company reputation on customer satisfaction by examining the company reputation and customer satisfaction of cargo companies in terms of university students.

Methodology- In order to achieve this aim, 280 students from Balikesir University Necatibey Education Faculty were obtained. Totally 245 questionnaires were analyzed.

Findings- First, variables are tested to be reliable and valid. After that relationship between the variables was observed by performing regression analysis.

Conclusion- As a result of the analysis, it has been determined that firm reputation affects customer satisfaction positively and significantly.

Keywords: Cargo companies, company reputation, customer satisfaction, validity, regression.

Jel Codes: M30, M31.

\section{KARGO FIRMALARININ MÜŞTERI MEMNUNIYETi VE FIRMA ITIBARI AÇISINDAN INCELENMESi}

ÖZET

Amaç- Bu çalışmanın temel amacı, üniversite öğrencileri açısından kargo firmalarının firma itibarının ve müşteri memnuniyetinin incelenmesiyle, firma itibarının müşteri memnuniyeti üzerindeki etkisinin belirlenmesidir.

Yöntem- Bu amaca ulaşmak için, Balıkesir Üniversitesi Necatibey Eğitim Fakülte'sinde öğrenim gören 280 öğrenciden veriler elde edilmiştir. Toplam 245 anket dikkate alınarak analizler gerçekleştirilmiştir.

Bulgular- Öncelikle değişkenlerin güvenilir ve geçerli oldukları test edilmiştir. Devamında regresyon analizi yapılarak değişkenler arası ilişki gözlenmiştir.

Sonuç- Yapılan analizler sonucunda, firma itibarının müşteri memnuniyetini pozitif ve anlamlı bir şekilde etkilediği belirlenmiştir.

Anahtar Kelimeler: Kargo firmaları, firma itibarı, müşteri memnuniyeti, geçerlilik , regresyon. Jel Kodları: M30, M31.

\section{GiRiş}

Kargo kavramı, "yük taşıyan uçak veya gemi; ; bir şirketin taşıdığı yük veya posta; bir yerden bir yere yük veya posta taşıyan şirket; uçak, gemi vb. bir taşıtla taşınan eşya, yük" şeklinde Türk Dil Kurumu tarafından tanımlanmaktadır _(TDK, 2018). Kargo hizmetleri lojistik eylemleri adı altında isimlendirebilir (Thai ve Grewal, 2005, p. 4). Kargo hizmetleri, müşterilerin hayatını kolaylaştıran en önemli araçlardan biridir. Günlük hayatımızda kurumsal ve bireysel olarak farklı alanlarda kargo gönderimi ve alımı yapılmaktadır. Dolayısıyla kargo sektörü, yoğun rekabet ortamında yer alan bir sektör olarak ekonomide varlığını sürdürmektedir. Kargo firmalarının pazar ortamındaki rolleriyle ile beraber sağladıkları hizmetler, tarafların karşılıklı olarak değerlendirmesinde geçmişe nazaran son derece önemli bir hal almaya başlamıştır. 
Ekonominin gelişmesi ve büyümesi insanların toplumsal yaşamını etkilemektedir ve aynı zamanda seğiştirmektedir. Bu etkileşim ve değişim sonucunda meydana gelen ihtiyaçlar, kargo hizmet sektörünü canlandırmıştır (Simona ve Maggi, 2003, p. 492).

Kargo firmalarının müşteri gönderi ve alımlarının gerçekleşmesinde önemli bir rol oynadığından, kargo taşımacılı̆̆ı yapan firmaların hizmet kalitesi müşteriler açısından gözlemlenen bir durumdur. Bu sektörde yer alan firmalar müşterilerine güvenilir ve hızlı taşımacılık imkânı sunar ve müşteri beklentilerine uygun çözümler üretirler. Müşterilerin gönderim ve alım işlemlerini gerçekleştirmesi kargo hizmetlerini kullanmalarına ve hizmetin kalitesi ölçüsünde müşteri memnuniyetinin analiz edilmesine yardımcı olmaktadır. Bununla birlikte, literatür taraması incelendiğinde kargo firmalarının sağladıkları hizmetlerin müşteriler tarafından değerlendirilmesine yönelik araştırmaların kısıtı olması, bu araştırmanın önemini vurgulamaktadır. Bu sebeple, bu çalışma, kargo firmalarının hizmet kalitesini geliştirilmesi ve iyileştirilmesi açısından önemlidir.

\section{LITERATÜR INCELEMESI}

\subsection{Firma İtibarı}

Firma itibarı; rakipler, müşteriler, endüstri analistleri ve müşterilerin işletmeyi algılama şeklidir. İşletmenin finansal durumu, rekabetteki etikliği, stratejileri, personelinin kalitesi, sosyal ve toplumsal sorumlulukları, yönetim kapasitesi, nitelikli iş göreni uzun dönem yatırımlarının değeri, gelişme düzeyi gibi faktörlerde müşteriler açısından nasıl algılandığını ifade etmektedir ve bu faktörler ile birlikte ölçülmelidir (Mishalisin ve Smith, 1997).

Firma itibarı, işletmeler açısından incelendiğinde büyük bir önem arz etmektedir. Bu nedenle, maliyetlerini azaltır, rekabet avantajı ve sürdürülebilirlik elde edilir, finansal çıktıları pozitif şekilde etkiler, müşteri güveni ve bağıılığın sağlanması yönünde artış sağlar ve işletmenin başarıları elde etmesinde önemli bir faktör olarak rol oynamaktadır (Walsh ve Beatty, 2007, p. 127-143). Aynı zamanda firma itibarı, firmanın performansını etkileyen ve müşterilerle firma arasında başarılı ilişkileri ortaya çıkaran bir faktördür (Ewing, Caruana ve Loy, 1999, p. 121).

\subsection{Müşteri Memnuniyeti}

Müşteri memnuniyeti "tatminkârlık ve tatmin olmama seviyeleriyle birlikte, bir ürün ya da hizmetin herhangi bir özelliğinden ya da tamamen kendisinden, tüketimle ilgili keyif alıcı tatminkârlık olgusu” şeklinde açıklanmaktadır. (Oliver, 2003, p. 46-47). Hizmet sektöründe ise "müşterilerin bir hizmete yönelik beklentileriyle birlikte hizmet deneyiminin karşılaştırılması neticesinde ortaya çıkan, hizmete dair duygusal ve bilişsel tepki" olarak ifade edilmektedir. Müşteri memnuniyeti davranış olarak değil, aynı zamanda algılama ve beklentilerle birlikte meydana gelen bir duygu olayıdır (Sandıkçı, 2007: 43).

Müşteri memnuniyetinin ölçülmesinde Day (1977) iki farklı yöntem üzerinde durmaktadır. Birincisi; müşterinin ürün veya hizmeti kullanması sonucunda tek bir ifade ile tatmin düzeyleri hakkında bilgilerin yer almasıdır. İkinci; müşterinin ürün veya hizmetin farklı bileşenlerine yönelik tatmin seviyeleri birden fazla ifadenin bulunduğu ölçek ile ölçülmesiyle beraber, ortalaması hesaplanarak tatmin seviyesi hakkında bilginin edinilmesidir (Day, 1977).

\subsection{Firma İtibarı ve Müşteri Memnuniyeti Üzerine Yapılan Çalışmalar}

Bu araştırma için yapılan literatür incelemesi neticesinde aşağıda yer alan araştırmalar ile karşılaşılmıştır.

Firma itibarı ve müşteri memnuniyeti ilişkilerinin incelendiği 462 cevaplayıcı ile gerçekleştirdikleri çalışmalarında firma itibarı ve müşteri memnuniyeti arasında güçlü bir ilişki tespit etmişleridir (Walsh, Dinnie ve Wiedmann, 2006). 2016 yılında İran'da yapılan bir araştırmada 251 Bank Melli müşterisinden toplanan veriler analiz edildiğinde firma itibarının müşteri memnuniyeti üzerinde pozitif yönlü bir etkisi olduğu sonucuna ulaşılmıştır (Pool, Pool ve Taghipourian, 2016). 2015 yılında Balıkesir ilinde yapılan otobüs firma müşterileri üzerinde yapılan bir çalışmada 355 kişi üzerinde bir uygulama yapılmış firma itibarının müşteri memnuniyeti üzerinde pozitif ve anlamlı bir etkisi olduğu gözlemlenmiştir (Koç, Günalan, Özbek ve Çinar, 2015). Bu çalışma için aşağıda yer alan hipotez ve model hazırlanmıştır.

H1: Kargo firmalarının sahip olduğu firma itibarının müşteri memnuniyetini anlamlı ve pozitif bir şekilde etkilemektedir.

\section{Şekil 1: Araştırmanın Modeli}

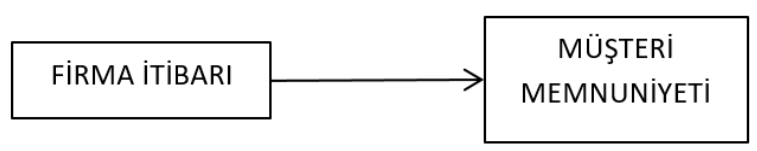

\section{YÖNTEM}

Bu çalışmanın temel amacı, üniversite öğrencileri açısından kargo firmalarının firma itibarının ve müşteri memnuniyetinin incelenmesiyle, firma itibarının müşteri memnuniyeti üzerindeki etkisinin belirlenmesidir. Araştırmanın amacına ulaşmak için ihtiyaç duyulan veriler, OcakŞubat 2018 tarihinde Balıkesir Üniversitesi Necatibey Eğitim Fakültesinde öğrenim gören 245 öğrenciden anket yöntemi ile toplanmıştır. Örneklem seçiminde kolayda örnekleme yöntemi kullanılmıştır. Anket formunun birinci bölümünde demografik özelliklere ve hizmet satın alınan kargo firmasına iişkin bazı temel bilgileri ölçmeye dayalı sorular yer almaktadır. İkinci bölümde ise, araştırmanın modelini, oluşturan değişkenleri ölçmeye dayalı sorular yer almaktadır. Firma itibarı; Casalo, Flavian ve Guinaliu'nun (2007) araştırmasından alınan 5 soru ve müşteri memnuniyeti ölçeği ise, Swaen ve Chumpitaz'ın (2008) araştırmasından 4 soru ile ölçülmüştür. Araştırma kapsamında kullanı firma 
itibarı ve memnuniyet ölçekleri 5'li likert ölçeğine (Kesinlikle katılmıyorum (1), Katılmıyorum (2), Ne Katılıyorum Ne Katılmıyorum (3), Katılıyorum (4), Kesinlikle Katılıyorum) göre düzenlenmiştir.

\section{BULGULAR}

\subsection{Demografik Bulgular}

Araştırmaya katılanlar demografik açıdan incelendiğinde, \%60,4'ü kadın, \%39,6'sı erkek olduğu görülmektedir. Katılımcıların, \%74,7'si 18-22 yaş aralığında, \%23,7'si 23-27 yaş aralığında ve \%1,6'sı 28 ve üzeri yaş aralığındadır. Cevaplayıcıların, \%20,4'ü 0-499 gelire, \%37,6'sı 500-999 gelire, \%26,1'i 1000-1499 gelire ve \%15,9'u 1500 ve üzeri aylık gelire sahiptir. Katılımcıların demografik özelliklerine ilişkin Frekans Analizi sonuçları Tablo 1'de sunulmuştur.

Tablo 1: Cevaplayıcıların Demografik Özellikleri

\begin{tabular}{|c|c|c|c|c|c|c|c|c|}
\hline Yaş & Frekans & Yüzde & Aylık Geliriniz & Frekans & Yüzde & Cinsiyet & Frekans & Yüzde \\
\hline $18-22$ & 183 & 74,7 & $0-499$ & 50 & 20,4 & Kadın & 148 & 60,4 \\
\hline $23-27$ & 58 & 23,7 & $500-999$ & 92 & 37,6 & Erkek & 97 & 39,6 \\
\hline 28 ve üzeri & 4 & 1,6 & 1000-1499 & 64 & 26,1 & Toplam & 245 & 100 \\
\hline Toplam & 245 & 100 & $\begin{array}{l}1500 \text { ve üzeri } \\
\text { Toplam }\end{array}$ & $\begin{array}{c}39 \\
245\end{array}$ & $\begin{array}{l}15,9 \\
100\end{array}$ & & & \\
\hline
\end{tabular}

Tablo 2'de araştırmaya katılan cevaplayıcıların hizmet satın aldığı kargo firmaları ile ilgili bilgiler yer almaktadır. Buna göre, çalışmaya katılan öğrencilerin en fazla Yurtiçi Kargo firmasını tercih ettikleri ve en az Sürat Kargo firmasını tercih ettikleri görülmektedir. Bununla birlikte, öğrencilerin en fazla tercih ettikleri firmalar sırasıyla Aras Kargo, PTT Kargo ve MNG Kargo'dur.

Tablo 2: Cevaplayıcıların Hizmet Satın Aldığı Kargo Firmaları

\begin{tabular}{lll}
\hline Kargo Firma İsmi & Frekans & Yüzde \\
\hline Yurtiçi Kargo & 104 & 42,4 \\
MNG Kargo & 31 & 12,7 \\
Aras Kargo & 47 & 19,2 \\
PTT Kargo & 46 & 18,8 \\
Sürat Kargo & 17 & 6,9 \\
Toplam & $\mathbf{2 4 5}$ & $\mathbf{1 0 0 , 0}$ \\
\hline
\end{tabular}

\subsection{Geçerlilik ve Güvenilirlik Analizi}

Çalışmada faktör analizinin gerçekleştirilebilmesi amacıyla gerekli olan KMO (Kaiser-Meyer-Olkin) örneklem yeterlilik katsayısı 0,895 ve evren korelâsyon matrisinin birim matris olmadığını gösteren Bartlett küresellik testinin p değeri 0,001 olarak hesaplanmıştır. Tablo 3'te geçerlilik ve güvenilirliğine ilişkin analiz sonuçları sunulmuştur.

\section{Tablo 3: Faktör ve Güvenirlilik Analizi}

\begin{tabular}{|c|c|c|c|c|}
\hline Modelde Kullanılan Ölçekler & $\begin{array}{l}\text { Faktör } \\
\text { Yükleri }\end{array}$ & Özdeğer & $\begin{array}{l}\text { Açıklanan } \\
\text { Varyans }\end{array}$ & Cronbach's Alpha \\
\hline \multicolumn{5}{|l|}{ FIRMA іTIBARI } \\
\hline $\begin{array}{l}\text { F1 Hizmet satın aldığım kargo firması, müşteriler gözünde iyi } \\
\text { bir itibara sahiptir. }\end{array}$ & 0,863 & \multirow{5}{*}{3,939} & \multirow{5}{*}{43,762} & \multirow{5}{*}{0,839} \\
\hline $\begin{array}{l}\text { F2 Hizmet satın aldığım kargo firması, rakiplerinden daha iyi bir } \\
\text { itibara sahiptir. }\end{array}$ & 0,810 & & & \\
\hline $\begin{array}{l}\text { F3 Hizmet satın aldığım kargo firması, iyi hizmet sunduğu } \\
\text { bilinen bir firmadır. }\end{array}$ & 0,747 & & & \\
\hline $\begin{array}{l}\text { F4 Hizmet satın aldığım kargo firması, müşterilerine karşı } \\
\text { hakkaniyetli davrandığı bilinen bir firmadır. }\end{array}$ & 0,743 & & & \\
\hline $\begin{array}{l}\text { F5 Hizmet satın aldığım kargo firmasının toplumdaki genel } \\
\text { imajı olumludur. }\end{array}$ & 0,626 & & & \\
\hline \multicolumn{5}{|l|}{ MÜŞTERI MEMNUNIYETI } \\
\hline $\begin{array}{l}\text { MM1 Akraba ve dostlarımı hizmet satın aldığım kargo } \\
\text { firmasını tercih etmeleri konusunda teşvik etmeyi } \\
\text { düşünmekteyim. }\end{array}$ & 0,858 & \multirow{3}{*}{1,595} & \multirow{3}{*}{17,722} & \multirow{3}{*}{0,754} \\
\hline $\begin{array}{l}\text { MM2 Kargo alım/gönderim hizmetleri konusunda bir problem } \\
\text { yaşasam bile hizmet satın aldığım kargo firması ile çalışmaya } \\
\text { devam ederim. }\end{array}$ & 0,791 & & & \\
\hline $\begin{array}{l}\text { MM3 Hizmet satın aldığım kargo firması, sunduğu hizmetlerin } \\
\text { fiyatını bir miktar artırsa bile, hizmet almaya devam etmeyi }\end{array}$ & 0,691 & & & \\
\hline
\end{tabular}


düşünüyorum.

MM4 Hizmet satın aldığım kargo firmasının sunduğu

hizmetler için, rakip firmalara göre, daha fazla ödeme yapmayı göze alabilirim.

Çıkarım Metodu: Principal Component Analysis.

Döndürme Metodu: Varimax with Kaiser Normalization.

Açıklanan Toplam Varyans: 61,484

\subsection{Regresyon Analizi}

Araştırmada ele alınan değişkenler arasındaki ilişki bir model yardımı ile ele alınmıştır. Model, regresyon analizi ile test edilmiştir. Gerçekleştirilen analiz sonucunda, firma itibarının memnuniyeti pozitif ve anlamlı bir şekilde etkilediği tespit edilmiştir. Yapılan analizler aşağıdaki tabloda sunulmuştur.

\section{Tablo 5: Firma İtibarının Müşteri Memnuniyeti Üzerindeki Etkisi}

\begin{tabular}{|c|c|c|c|c|c|}
\hline Model & & $\begin{array}{l}\text { Standartlaştırılmış } \\
\text { Beta }\end{array}$ & $\mathbf{t}$ & Anlamlılık & $\begin{array}{l}\text { Modele ilişkin } \\
\text { Değerler }\end{array}$ \\
\hline 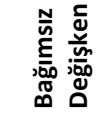 & Firma İtibarı & ,452 & 7,896 & $0,001 *$ & $\begin{array}{l}\mathrm{R}^{2}=0,204 \\
\mathrm{~F}=62,347 \\
\text { Anlam }=0,001\end{array}$ \\
\hline
\end{tabular}

Bağımlı değişken: Müşteri Memnuniyeti

* 0,01'a göre anlamlıdır.

\section{SONUÇ VE ÖNERILER}

Yazın taraması incelendiğinde, bir firmanın sahip olacağı firma itibarının müşteri memnuniyetini pozitif bir şekilde etkileyeceğine dair araştırmalar yer almaktadır (Walsh, Dinnie ve Wiedmann, 2006; Walsh ve Beatty, 2007; Loureiro ve Kastenholz, 2011; Saeidi, Sofian, Saeidi, Saeidi ve Saeidi, 2015; Sengupta, Balaji ve Krishnan, 2015). Literatür incelemesi ile bu araştırmanın sonuçları arasında paralelik olduğu görülmektedir. Yapılan analizler neticesinde elde edilen sonuç, öğrencilerin kullandıkları kargo firma itibarının müşteri memnuniyetini pozitif ve anlamlı bir şekilde etkilediği belirlenmiştir. Buradan hareketle, artan itibarın müşteri memnuniyetini olumlu yönde etkileyebileceği ve böylelikle kargo firmalarına bağlı müşteriler oluşturulabileceği göz önünde bulundurulmalıdır. Araştırma sonucuna göre, kargo sektöründe faaliyette bulunan firmalar, müşteri memnuniyetini oluşturmak ve devamlılı̆ını sağlamak amacıyla, firma itibarını ve müşterinin algılayacağı değerler üzerinde durup, karşılaşılan sorunlar için yeni çözümler üretmeleri gerekliliği söylenebilir.

$\mathrm{Bu}$ araştırma ile birlikte, araştırmacılara ve uygulayıcılara çeşitli öneriler sunulmuştur. Araştırma kapsamı, kargo sektörü özelinde gerçekleştirilmiştir. Yapılacak araştırmalarda, bu çalışmadaki değişkenler farklı sektörler ve kitleler üzerinde kullanılabilir. Araştırma zaman ve maliyet kısıtı sebebiyle kolayda örnekleme yöntemi ile belirlenmiş ve üniversite öğrencileri üzerinde gerçekleştirilmiştir. Alanyazında ulaşılan çalışmalarda bu örnekleme yöntemi kullanılmış olmasına rağmen tesadüfî örnekleme yöntemlerinden birinin kullanılması sonuçların genellenebilirliği bakımından önemlidir.

\section{KAYNAKÇA}

Casalo, V. L., Flavian, C., Guinaliu, M. (2007). The role of security, privacy, usability and reputation in the development of online banking. Online Information Review, 31(5), p. 583-603.

Day, R. L. (1977). Extending the concept of consumer satisfaction. Atlanta: Association of Consumer Research, 4, p. $149-154$.

Ewing, M. T., Caruana, A., Loy, E. R. (1999). Corporate reputation and perceived risk in professional engineering services. Corporate Communications: An International Journal, 4(3), p. 121-128.

Koç, Günalan, Özbek, Çinar (2015). Şehirlerarası otobüs firmalarının ulaşılabilirliğinin memnuniyet. Firma İtibarı ve Algılanan Değer Üzerindeki Etkisi, International Review of Economics and Management, 3(1), s. 39-60.

Loureiro, S. M. C., Kastenholz, E. (2011). Corporate reputation, satisfaction, delight, and loyalty towards rural lodging units in Portugal. International Journal of Hospitality Management, 30(3), p. 575-583.

Mishalisin, M. D., Smith, R. D. (1997). Startegic planing source. International Journal of Organizational Analisis, 5(4), 111.

Oliver, R. L. (2003). Satisfaction: A behavioral perspective on the consumer. Boston, MA: Irwin, McGraw- Hill, 13.

Pool, A. K., Pool, M., Taghipourian, M. (2016). Customer satisfaction through corporate reputation: the mediating role of perceived value. Internatıonal Journal of Humanitıes and Cultural Studies, Volume 3 Issue 2 s. 1424-1434. 
Saeidi, S. P., Sofian, S., Saeidi, P., Saeidi, S. P., Saeidi, S. A. (2015). How does corporate social responsibility contribute to firm financial performance? The mediating role of competitive advantage, reputation, and customer satisfaction. Journal of Business Research, 68(2), p. 341-350.

Sandıkçı, M. (2007). Müşteri memnuniyeti ölçülmesi ve Dandıklı Hüdai Kaplıcası'nda bir alan çalışması. Afyon Kocatepe Üniversitesi, iïBF Dergisi, 9(2), s. 39-53.

Sengupta, A. S., Balaji, M. S., Krishnan, B. C. (2015). How customers cope with service failure? A study of brand reputation and customer satisfaction. Journal of Business Research, 68(3), p. 665-674.

Simona, B., R. M. (2003). Logistic strategy and transport service choives: an adaptive stated preference experiment. Growth and Change, Fall, 2003, 34(4), p. 490-504.

Swaen, V., Chumpitaz, R. C. (2008). Impact of corporate social responsibility on consumer trust. Recherche at Applications in Marketing, 23(4), p. 7-33.

TDK (2018). Atatürk Kültür, Dil ve Tarih Yüksek Kurumu, http://www.tdk.gov.tr/

Thai, V. V., Grewal, D. (2005). Selecting the location of distribution centre in logistics operateons: a conceptual framework and case study. Asia Pasific Journal of Marketing and Logistics, 17(3), p. 3-24.

Walsh, G., Beatty, S. E. (2007). Customer-based corporate reputation of a service firm: scale development and validation. Journal of the Academy of Marketing Science, 35(1), p. 127- 143.

Walsh, G., Dinnie, K., Wiedmann, K. (2006). How do Corporate reputation and customer satisfaction impact customer defection? A study of private energy costumers in Germany. Journal of Services Marketing, 20(6), p. 412-420. 